\title{
Leberblümchen (Hepatica nobilis), Blume des Jahres 2013
}

\author{
Kurt Baumann
}

\begin{abstract}
Liverleaf (Hepatica nobilis) is flower of the year 2013. Its biology, ecology and medicinal use are outlined.
\end{abstract}

\section{Zusammenfassung}

Das Leberblümchen (Hepatica nobilis) ist Blume des Jahres 2013. Biologie, Ökologie und Nutzen als Heilpflanzen werden vorgestellt.

\section{Einführung}

Das Leberblümchen (Hepatica nobilis, Ranunculaceae) wurde früher zur Gattung Anemone gestellt. Durch die dicht unterhalb der Blüte stehenden Hochblätter (s. u.) unterscheidet es sich von Buschwindröschen. Der deutsche Name sowie der wissenschaftliche Gattungsname Hepatica beziehen sich auf die Leber. Nach der mittelalterlichen Signaturlehre weisen Pflanzen mit ihrer Farbe oder Form auf eine von Gott gegebene Verwendung als heilendes Objekt hin. Die rotbraune Farbe der Blattunterseite erinnert an die Farbe der Leber, weshalb das Leberblümchen bei Leberleiden zu verwen- den war. Immer wieder wird auch genannt, dass die dreilappige Form an die Leber erinnere. Die menschliche Leber ist jedoch zweilappig und die Ähnlichkeit der Formen ist nur sehr grob. Der Name Edelleberkraut ist schon in Volksbüchern des 16. Jahrhunderts vorhanden als Gegensatz zum Leberkraut, dem Brunnenlebermoos. Volksnamen wie Blaublume oder Blauäugelein (im Hannoverischen) beziehen sich auf die Blütenfarbe, die frühe Blütezeit

Abb. 1: Junge Blüten des Leberblümchens am Gau-Algesheimer Kopf.

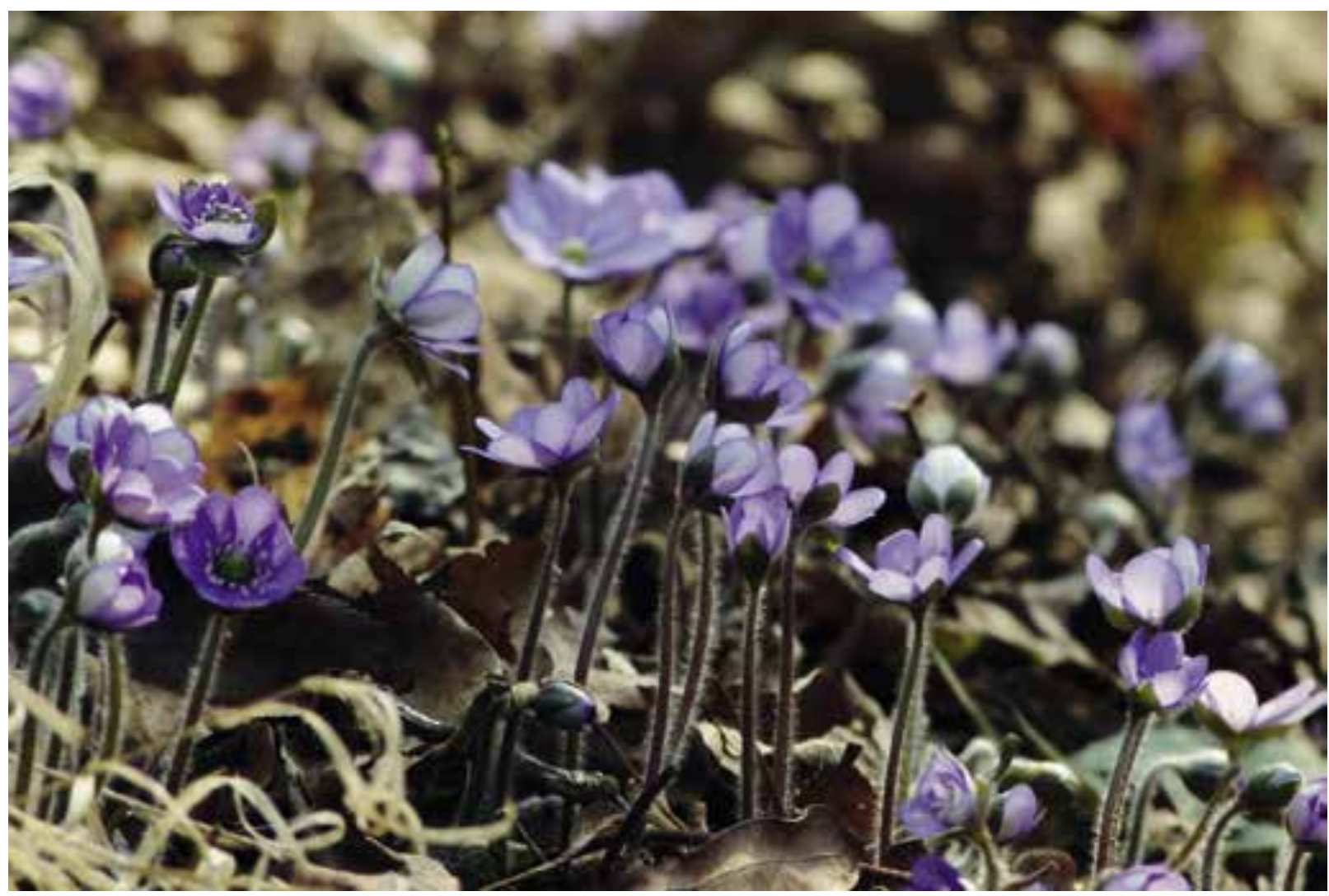




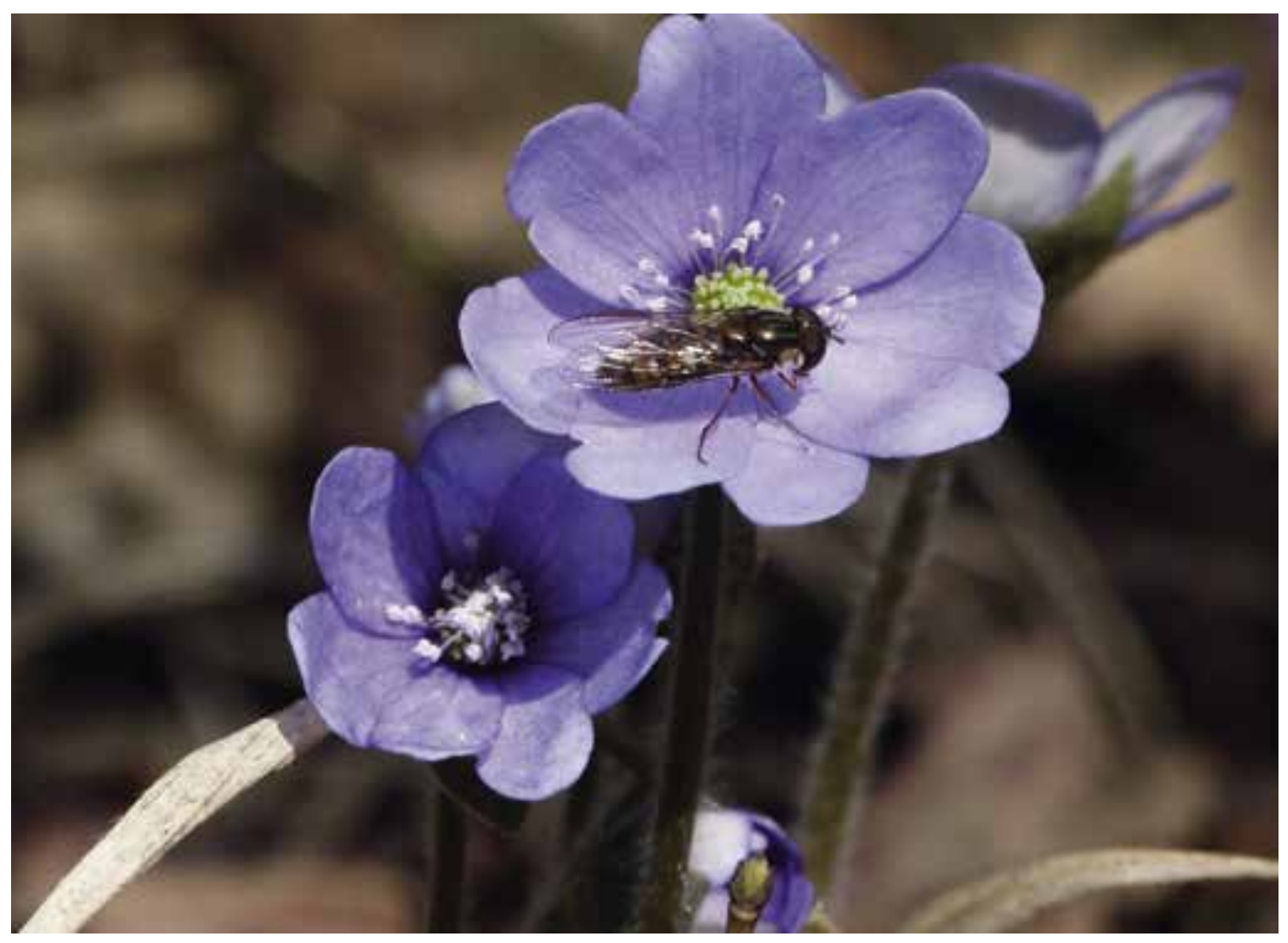

führte zu den Bezeichnungen Vorwitzchen und Märzblume. Den Waldstandort spricht Holzblümeli an, während das Auftreten von Blüten und Blättern (ähnlich wie bei der Herbstzeitlose) im Norddeutschen Dialekt zum Namen Dochter vor de Modder führte.

\section{Standort und Verbreitung}

Es wird angenommen, dass das Leberblümchen erst in der Nacheiszeit von Osten her nach Mitteleuropa eingewandert ist. Die Einwanderung erfolgte sehr langsam (etwa $1 \mathrm{~km}$ in $200 \mathrm{Jah}-$ ren), da die Samen des Leberblümchens von Ameisen nur langsam (im Umkreis der Mutterpflanze) ausgebreitet werden (SCHUHWERK et al. 1978). Das Leberblümchen stellt hohe Ansprüche an den Nährstoffgehalt des Bodens und gilt in Deutschland als eine der besten Zeigerpflanzen für Kalk- und Lehmböden. Es ist eine Halbschatten- bis Schattenpflanze, die auf hohe Temperaturen und Austrocknung empfindlich reagiert. Es gedeiht in der Krautschicht mäßig trockener bis frischer, kalkreicher Laub- mischwälder, im Osten auch in Nadelmischwäldern auf humusreichen Lehmböden. Es fühlt sich besonders wohl in alten Buchen- und Eichenwäldern. Als Zierpflanze in verschiedenen Sorten bereichert das Leberblümchen vielerorts unsere Gärten (RÜTHER 2008).

In den nährstoffarmen Böden der norddeutschen Altmoränenlandschaft und in den silikatreichen Mittelgebirgen wie Harz, Thüringer Wald, Erzgebirge, Böhmerwald, Schwarzwald und den hessischen Mittelgebirgen kommt das Leberblümchen nicht vor. Es fehlt auch im Tiefland westlich der Weser und in Hamburg. In den westlichen Bundesländern ist das Leberblümchen selten. In Rheinland-Pfalz be-

Abb. 2 (oben): Leberblümchen mit Besuch einer Schwebfliege.

Abb. 3 (Seite 55 oben): Detail einer Blüte mit zahlreichen Staubblättern.

Abb. 4 (Seite 55 unten): Die dreilappigen Blätter des Leberblümchens. 
schränkt sich sein Areal auf zwei Messtischblätter (z. B. Gau-Algesheim). Eine Westgrenze der Verbreitung ist der Teutoburger Wald. Häufiger tritt es in Baden-Württemberg (jedoch nicht im Schwarzwald), im bayrischen Alpenvorland und in den Alpen bis $1500 \mathrm{~m}$ Höhe auf. Es kommt auch in den östlichen Bundesländern Thüringen, Sachsen-Anhalt und MecklenburgVorpommern vor. Im Westen Europas ist es in Nordostspanien zu finden, im Süden reicht sein Areal bis auf den Apennin, im Norden bis nach Südfinnland und im Osten über Polen, Tschechien und den Balkan bis zur oberen Wolga (Haeupler \& Schönfelder 1988, Benkert et al. 1996).

\section{Bedrohung und Schutz}

Die Bestände des Leberblümchens sind vielerorts im Rückgang begriffen. Die Verminderung der Leberblümchen-Populationen hängt damit zusammen, dass alte, ungestörte Wälder immer seltener werden und die Laubmischwälder durch den Anbau von Nadelholzmonokulturen (von denen man aber inzwischen schon abgekommen ist) verschwunden sind. Schädigend für das Leberblümchen sind auch der Maschineneinsatz und der Wegebau in der Forstwirtschaft, weniger das Ausgraben für Hausgärten. Der Rückgang des Leberblümchens hat die LoKi-SchmidT-Stiftung dazu bewogen, Hepatica nobilis zur Blume des Jahres 2013 zu wählen. Gleichzeitig soll auf die Bedrohung alter Wälder, die idealen Lebensräume des Leberblümchens, hingewiesen werden.

\section{Bau der Pflanze}

Das Leberblümchen ist mehrjährig und kann mehrere Jahrzehnte alt werden. Sein dunkelbraunes Rhizom liegt schräg im Boden und ist mit schuppenförmigen Niederblättern besetzt. Als Tiefwurzler können die Wurzeln bis in Tiefen von einem halben Meter vordringen. Die am Grunde herzförmigen Blätter sind bis zur Hälfte dreiteilig eingeschnitten. Ihre breit eiförmigen, stumpfen Lappen sind ganzrandig, in der Jugend wie die Stiele dicht weißseidig behaart. Unterseits sind die ledrigen Blätter rotbraun bis violett gefärbt. Die Blätter bleiben bis
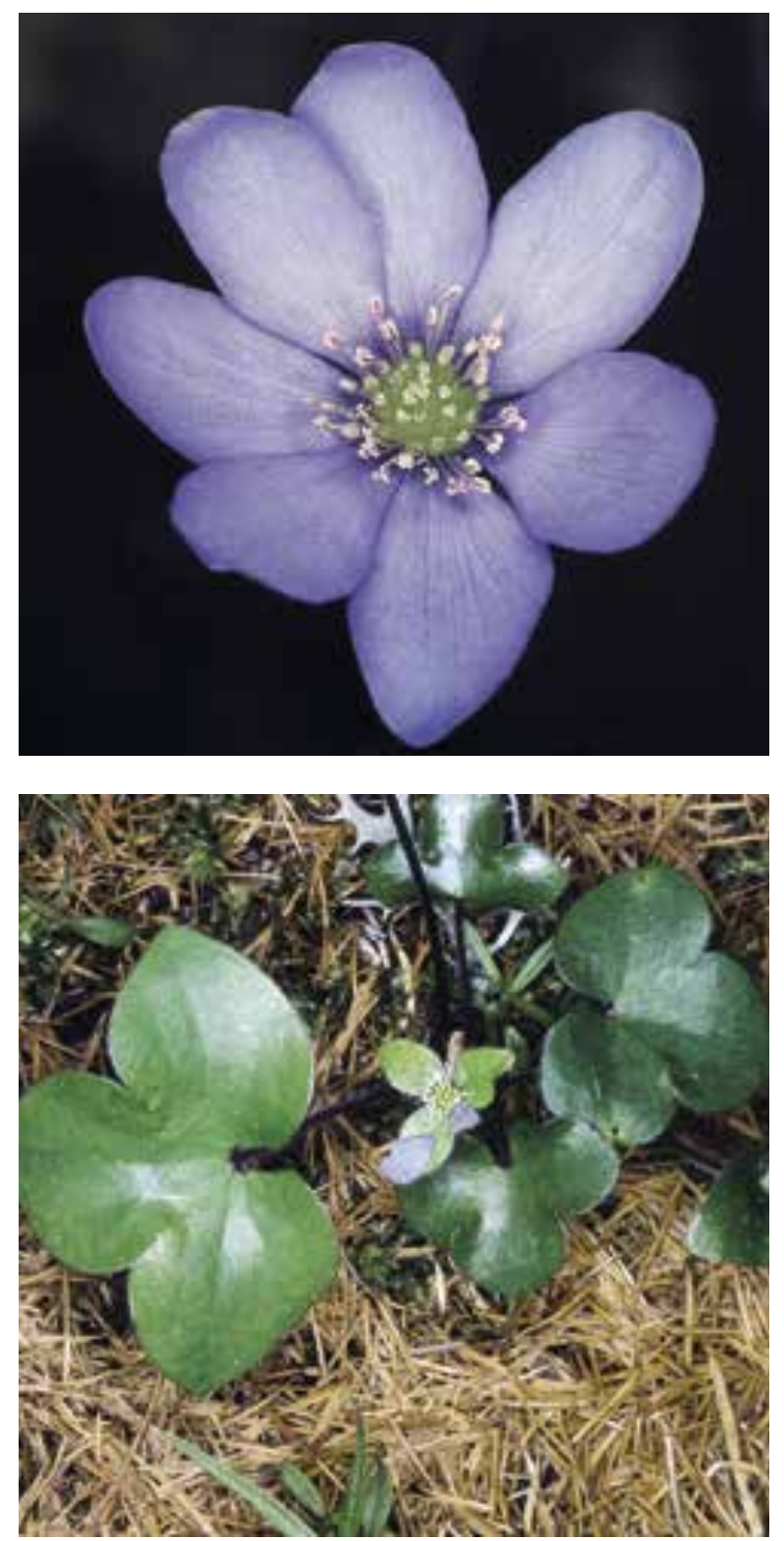

zur Blütezeit im nächsten Jahr erhalten, somit ist das Leberblümchen wintergrün.

\section{Blüte und Vermehrung}

Das Leberblümchen wird 5-15 (selten 25) cm hoch. Es blüht von März bis April, in höheren Lagen bis Juni. Die bis $3 \mathrm{~cm}$ breiten Blüten haben 5-10 schmale himmelblaue, selten rosa oder weiß gefärbte Blütenblätter. Diese entsprechen Kelchblättern. Wenige Millimeter unterhalb der Blütenhülle stehen drei quirlig angeordnete, grüne ovale, bis $1 \mathrm{~cm}$ lange Hochblätter. Die Blüten öffnen und schließen sich durch eine wärmeabhängige Wachstumsbewegung. Dies führt dazu, dass sich die Länge der Blütenblät- 


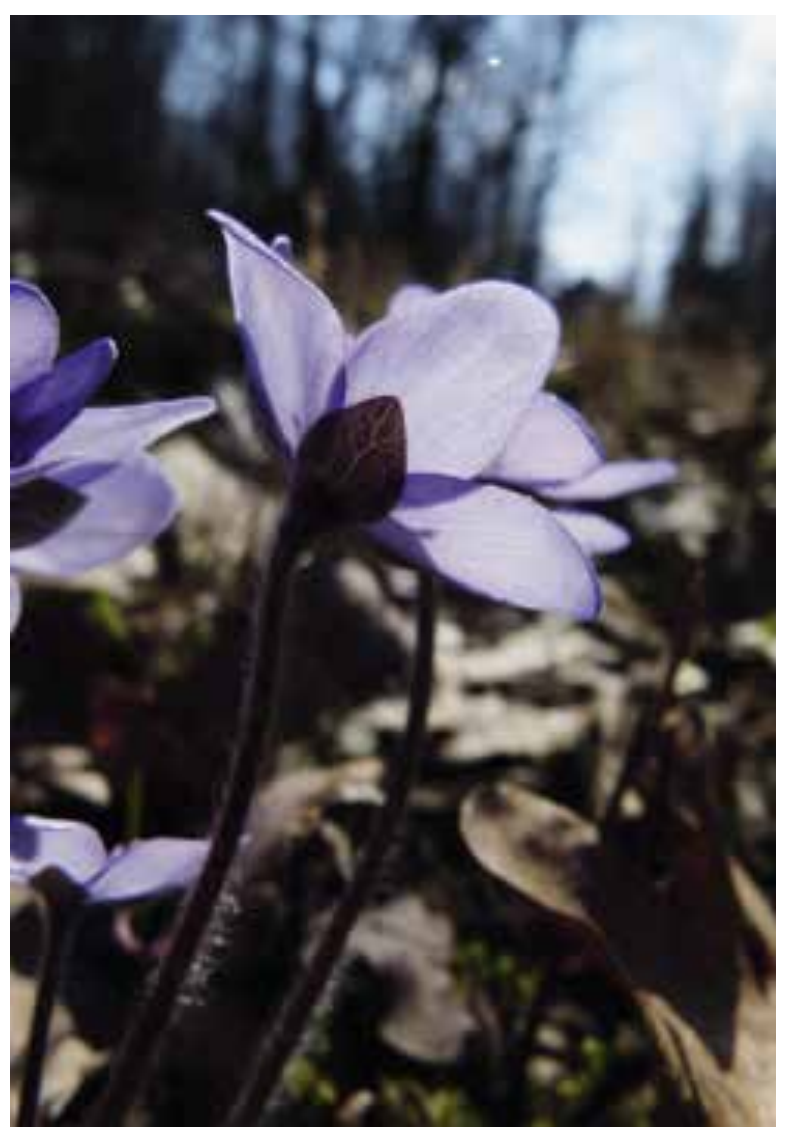

ter im Laufe der etwa einwöchigen Blühzeit verdoppelt. Die Blüte enthält zahlreiche Staubgefäße mit weißen Staubbeuteln und rotem Konnektiv sowie mehrere nicht verwachsene Fruchtblätter mit kopfigen Narben. Die Blüte bildet keinen Nektar. Als Bestäuber wurden verschiedene Pollen fressende Insekten wie Käfer, Bienen, Schwebfliegen und Schmetterlinge beobachtet. Auch Selbstbestäubung ist möglich. (DAmbolt et al. 1974, Düll \& KutZelnigg 2011).

Pro Blüte bilden sich mehrere einsamige, behaarte Nüsschen. Sie sind länglich und haben einen kurzen Schnabel. Die Hochblätter umschließen schützend die heranwachsenden Früchte. Der Blütenstiel neigt sich mit zunehmender Fruchtreife dem Boden zu, denn Leberblümchen sind Selbstaussäer. Das fleischige untere ölhaltige Anhängsel des Nüsschens (Elaiosom) dient Ameisen als Futter. Diese verschleppen die Früchte und tragen somit zur Ausbreitung des Leberblümchens bei. Die Samen benötigen für die Keimung einen Kältereiz und Licht. Die Jungpflanzen entwickeln sich sehr langsam und blühen erst nach einigen Jahren.

\section{Heilkraft}

Die früher vermutete Heilkraft des Leberblümchens konnte nach modernen pharmakologischen Untersuchungen nicht bestätigt werden. Deshalb wurde es aus dem Arzneimittelschatz der Apotheken gestrichen. Allerdings wird es noch homöopathisch bei Leberleiden und Bronchitis verwendet. Dazu wird aus dem frischen Kraut eine Essenz hergestellt. In der Volksmedizin wird das frische, zerquetschte Kraut äußerlich als Wundheilmittel angewendet. Diese Nutzung verbietet sich allerdings heutzutage, da das Leberblümchen gemäß Bundesnaturschutzgesetz geschützt ist. Außerdem ist Hepatica nobilis im frischen Zustand schwach giftig. Die Staude enthält Protoanemonin, wobei die Menge geringer als beim Buschwindröschen (Anemone nemorosa) ist. Der Saft des Leberblümchens kann zu Hautreizungen führen (Rотн et al. 1994). Innerlich eingenommen führt er zu Übelkeit, Durchfall und Nierenschädigung. Beim Trocknen verliert sich die Giftwirkung.

\section{Literatur}

Benkert, D., Fukarek, F., Korsch, H. 1996: Verbreitungsatlas der Farn- und Blütenpflanzen Ostdeutschlands. - Jena.

Damboldt, J. \& Zimmermann, W. 1974: Hepatica. In: Hegi, G.(Hrsg.) - Illustrierte Flora von Mitteleuropa. Bd. III,3., 2. Aufl. - München.

Düll, R. \& Kutzelnigg, H. 2011: Taschenlexikon der Pflanzen Deutschlands und angrenzender Länder.7. Aufl. - Wiebelsheim.

Haeupler, H. \& Schönfelder, P. 1988: Atlas der Farn- und Blütenpflanzen der Bundesrepublik Deutschland. - Stuttgart.

Roth, L., Daunderer, M. \& Kormann, K. 1994: Giftpflanzen - Pflanzengifte. 4. Aufl. - Hamburg. Rüther, P. 2008: Frühblüher. Neue Brehm-Bücherei, Bd. 661. - Hohenwarsleben.

Schuhwerk, F., Schönfelder, P. \& Haeupler, H. 1978: Musterkarten zum Stand der floristischen Kartierung in der BRD. - Götting. Flor. Briefe 12: 69-92.

Abb. 3: Seitenansicht einer Blüte mit kelchartigen Hochblättern. 